\title{
Research on Blended Learning Mode of SPOC-based Computer Science Course for the Deaf
}

\author{
Zhili Liu, Yan Li, Hanjing Li, Dengfeng Yao \\ Special Education College \\ Beijing Union University \\ Beijing, China \\ tjtzhili@buu.edu.cn
}

\begin{abstract}
As one of the traditional courses of higher education in China, computer science course for the de af college students has to be adjusted in teaching content, and the course presentation, learning mode as well. The traditional teaching mode should be blended for dynamic mode instead of static teaching, learning quality and efficiency to be improved. The writer in this paper, the refore, has designed the blended learning mode of SPOC-based computer science course from four phases including leading end analysis, resource design, activity design and teaching evaluation, and also designed teaching cases originated from the course of Database Principles and Applications with off-line teaching plus on-line activities and on-line learning plus off-line activities. At the end of this essay, a teaching experience has been carried out to test the assumption that this blended learning mode of SPOC-based course can really promote the teaching effect of computer science course, students' degree of satisfaction improved.
\end{abstract}

Keywords-SPOC; computer science course; blended learning; the deaf; special education

\section{INTRODUCTION}

Started in late 1980s, higher education for the deaf in China has been developing from extensive development featured with extensive style to connotative one of improving cultivation quality in the past 30 years, which mainly forms two education systems including normal higher education after college entrance examination and specially-set education in Special Education College, Department or Class after special examination in which the latter forms the main one of higher education for the deaf students.

As one of the two traditional majors in higher education for the deaf, the theory and practicability of computer science are hard to understand for students, especially those relying on visual learning with various loss of hearing ability. In the writer's opinion, to complete complicated knowledge teaching and be suitable for the fast course refreshment, ways of adjustment, refreshment and cutting in teaching are supposed to be carried out to meet the practical application, and also the course setting and learning mode have to be changed for the education development. That is to say, information technology and education resource must be blended comprehensively, which means on-line course enriches off-line ones and blended-learning mode replaces off-line learning to promote sharing of good resource. Therefore, the teaching process must be dynamic instead of being static, which can truly realize the idea of "differentiated and individual teaching for pertinence of education" mentioned in The Second Period of Special Education Promotion Plan (2017-2010). Cultivating self-learning ability and lifelong learning ability for deaf students is the effective method to shrink the gap between special education and general education.

\section{BLENDED LEARNING MODE AND SPOC}

Internet-based blended learning is a teaching strategy whose definition has evolved from broadness to refining; gradually focusing on $\mathrm{O} 2 \mathrm{O}$ mode blended off-line learning with on-line learning. And the broad blending contains various modes like teaching theories, teaching modes, teaching media, teaching surroundings and learning methods, etc. Driscol pointed out that the blended learning just presented its infinite possibilities $^{[1]}$. Reflecting E-learning, blended-learning recognizes the relationship between technology and human beings, which means the deep development of information and course integration. In Horizon Report in 2015, it was indicated that in the coming one or two years blended learning will become the core trend to improve the development of higher education informationization ${ }^{[2]}$. Compared with off-line learning only, blended learning is more advantageous. It is the present core that how we can take full play of the advantage of on-line learning in resource, time and space blended with convenient emotional communication and activity organization by means of off-line learning, which can enhance students learning ability and learning effect in blended learning surroundings.

The rising of MOOC enriches on-line learning resources and supplies new idea and method for blended learning because MOOC, a vast and free course taught by well-known lecturers from famous universities. The vast development of MOOC provides great opportunity for higher education development, so how to apply MOOC in traditional higher education is widely focused. As small-sized on-line course, SPOC, as a typical course mode in post MOOC period, integrated with the educational ides of MOOC, is also combined with Micro-lesson, minor teaching and intensified education, which forms a kind of education mode specially featured with SPOC ${ }^{[3]}$. According to Wikepedia, SPOC is a version of a MOOC used locally with college students. And other scholars explained that SPOC is MOOC plus off-line teaching ${ }^{[4]}$. Thus, it is indicated that SPOC itself is a blended learning mode. And SPOC-based blended learning contributes 
to effective application of the MOOC resources to meet different students' need. In SPOC-based blended learning mode, the role of a teacher will change to teaching resource designer, teaching organizer, explainer of difficulties and guider in learning. The original intention of SPOC is to combine superior MOOC resource with off-line teaching, flipped class to be realized, teaching structure reformed and teaching quality improved as well ${ }^{[5]}$.

\section{SPOC-BASED BLENDED LEARNING MODE OF COMPUTER SCIENCE COURSE FOR THE DEAF}

\section{A. Design of blended learning mode}

Referred to blended learning course design framework presented by Mr. Huang Ronghuai ${ }^{[6]}$ and SPOC application mode by MS. Yang $\mathrm{Li}^{[7]}$, four phases including leading end analysis, resource design, activity design and teaching evaluation are designed for SPOC-based blended learning mode for deaf students in learning computer science, which is illustrated in Figure one. Leading end analysis is the learning base, resource and activity design is the key point, and teaching evaluation is spiral test importance for learning effect and revising learning mode.

\section{1) Leading and Analysis}

Leading end analysis contains learner analysis, learning objective analysis and learning content analysis. Learner analysis is designed to prepare knowledge analysis and learning need analysis, basing on the character analyses like attention, memory, thinking and learning style in the condition of physiological deficiency. And learning objective analysis refers to objectives of knowledge, skill and quality to be reached, while learning content analysis covers the analyses of knowledge point, key point and difficulty contained in each knowledge mode.

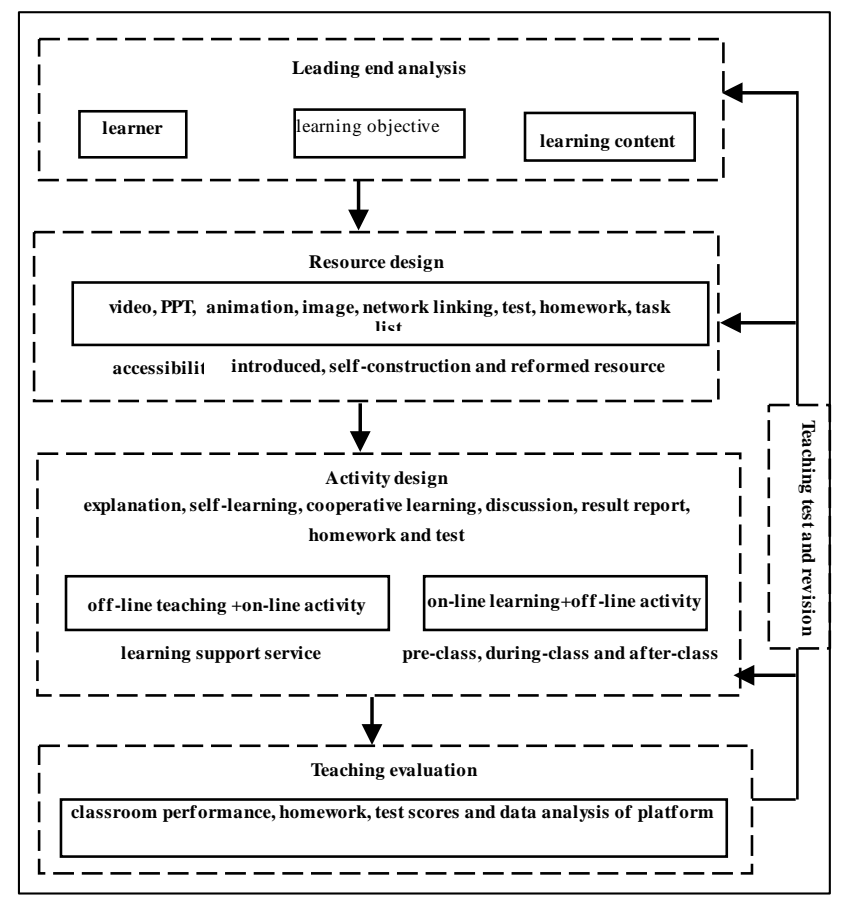

Fig. 1. SPOC-based blended learning mode of computer science course for deaf students

\section{2) Resource Design}

Containing various forms like video, PPT, animation, image, network linking, test, homework and task list and their extended resources, Blended learning resources are designed in three presentations including introduced resource, self-made resource and reconstruction resource by the designers in which introduced resource is to introduce existing superior resources to revise and adjust introduced resources on the basis of students' learning peculiarity and foundation. If the introduced or revised resources cannot meet the needs, self-made resource will be applied. Cored with resources of MOOC and self-constructed micro-video resources, SPOC-based blended learning resources take consideration of learners to realize accessible reading by means of added subtitle.

\section{3) Activity Design}

Activity design includes the activities to be carried out in three periods of before-class, during-class and after-class both in on-line and off-line learning. Two forms of design like off-line teaching plus on-line learning content and on-line learning plus off-line activity called flipped classroom are employed for kinds of activities like explanation, self-learning, cooperative learning, discussion, achievement report, task and test, etc. During design, learners act as the main roles so as to maintain their learning participation. At the same time, learning support in activity is designed for consistent learning and to stimulate their learning motivation, learning enthusiasm to be activated and self-learning ability to be cultivated.

\section{4) Teaching Evaluation}

Many evaluation forms are adopted to assess blended learning in which formative evaluation and summative evaluation are mixed together. Evaluation takes role to supervise and urge learners during the whole process of learning. The evaluation performs in different ways like off-line learning such as check-in, classroom performance and final scores, and the on-line platform record, for instance, login duration, learning resource downloading, learning and discussion participation, assignment and test results, etc.

\section{B. Teaching Case Design}

With the exampled course of "Database Principles and Applications”, teaching case for blended learning is designed during which on-line support platform is to be constructed. However, most video resources from MOOC platform without subtitle are available, which hinders deaf students from learning. This research, therefore, samples the SPOC-based blended learning mode selected from Blackboard Network Classroom of Beijing Union University, which is convenient for us to process the selected resources accessibly. Before the class, students are supposed to select one course released in China University MOOC and after comparison with subjects of database principles; we finally decided to employ Database Principles and Applications compiled by Professor Li Yanling from Northeast Normal University because it is closer to teaching objectives in teaching content and method. Learners are supposed to register and complete learning the whole course in this learning surrounding. After that, the application of network classroom in our university is introduced so that they can carry out individualized learning in a small circle. Learning subjective, knowledge points, key points, difficulties 
and students preparation of nine units are analyzed, suitable teaching method for individual knowledge point analyzed for the design of corresponding teaching resources and teaching activities and implementation of teaching evaluation.

1) Teaching Cases of Off-line Class Plus On-line Activity

As the main form of blended learning, off-line class plus on-line activity are adopted to extend space and time for learning so as to raise learning effect. "Database System" introduced in unit one explains concepts, development, basic procedure of database design. The basic concepts in unit one are to be lectured in off-line class, solid foundation for learning to be consolidated and the understanding of abstract concepts to be deepened by means of on-line test. The learning of database development can be completed by self-learning with the analysis of future development presented by test. Database design is the key point in this unit in which the MOOC video is supplied to illustrate during off-line teaching and task-driven method is applied to lead in the database design. During on-line learning, several topics are listed so that the learners can cooperate to finish related database design on the basis of their interest. Once any problems emerge, they can discuss in the discussion board with results achieved released on-line and reported off-line. Mutual recommendation from teachers and students are raised for further revision and released again. The teaching contents in this unit contains subtitled MOOC video, self-construction difficulties, lists of key concepts, basic concept tests, database development and its extended resources, database development trend and its design task, which will be indicated in Table one.

TABLE I. SPOC-BASED BLENDED LEARNING DESIGN SOLUTION

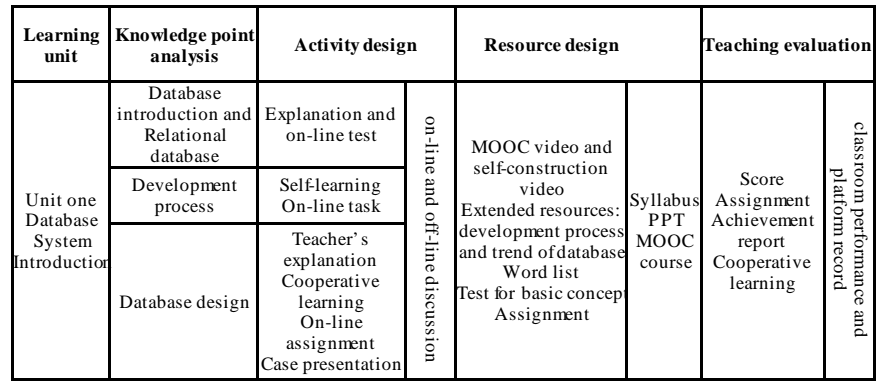

2) On-line Learning Plus off-line Teaching Cases

As a mixed learning, on-line learning plus off-line learning can be properly extended on the basis of student knowledge so as to encourage their initiative and improve interactive teaching. As one of the most frequently applied methods, inquiry in database study can deal with complicated structure in flexible clause. For the inquiry of single datasheet, flipped classroom of on-line learning plus off-line learning can be applied for a better guide in pre-layout learning and off-line teaching. During pre-class, learning resources of MOOC video like PPT, subtitled presentation can be uploaded on on-line platform, together with pre-class exercises. Meanwhile, learning task for pre-learning support has to be uploaded also, which is explained in Table two. Learning task list mainly contains various assignments and specific requirements, which ensures the objective of pre-learning in the premise that learners are supposed to submit pre-class exercises, learning difficulty to be mastered for purposed guidance during teaching. Off-line activities during teaching can change from traditional teaching to the one without pre-lecturing, which will weaken the reliance on teachers. Furthermore, self-learning and exploring will be cultivated, which will be claimed and assigned in task list. During teaching the teacher is supposed to analyze and explain existing problems in pre-class exercises. And in the following, students can be assigned to explain some key points and difficulties. Learning companions will set a good example to stimulate learners' initiative; on the other hand, it can also enhance their confidence in learning. After that, exercises or comprehensive tasks with a certain difficulty may be assigned for learners to complete knowledge transferring and creative application. As for after-teaching, the favorite presentations can be generalized for conclusion by learners themselves with means of drawing mind mapping, clear knowledge sequence of thought formed, knowledge consolidated and abstract capacity of generalization cultivated.

TABLE II. PRE-CLASS LEARNING T ASKS IN SINGLE DAT ASHEET INQU

\begin{tabular}{|c|c|c|}
\hline $\begin{array}{c}\text { Learning } \\
\text { content }\end{array}$ & Learning task & Learning objective \\
\hline \multirow{4}{*}{$\begin{array}{l}\text { Single datasheet } \\
\text { inquiry } \\
\text { in unit } 4\end{array}$} & Reading and watching PPT & $\begin{array}{l}\text { Reading segment one of unit four, watching PPT and } \\
\text { mastering basic structure of single datasheet inquiry } \\
\text { clause }\end{array}$ \\
\hline & Watching MOOC video & $\begin{array}{l}\text { Watching MOOC video and familiar with specific } \\
\text { usage of clauses in inquiry statements }\end{array}$ \\
\hline & Completing pre-class exercises & Handing out tested T-SQL statements in pre-teaching \\
\hline & Claiming tasks explaining during class & $\begin{array}{l}\text { Claiming tasks of sort and group clauses and prepaing } \\
\text { related materials }\end{array}$ \\
\hline
\end{tabular}

\section{TEACHING APPLICATION AND REFLECTION}

SPOC-based blended learning mode is applied in teaching the course of "Database Principles and Applications" among students of 2016-2017 semester to enrich content, refresh teaching ways and reform teaching structure. Teaching experiment is employed to test that it is really helpful to promote teaching effect of computer science. During this term the course lectured obtained the highest assessment ever since, excellent teacher certificate evaluated, which illustrated that this mode raised students' satisfaction. It agreed with the idea that "SPOC applied in classroom can develop teaching methods, students' interactive learning and participation, together with their mastery degree of knowledge” ${ }^{[8]}$. During application, after consistent reflection, the writer provides tested example that the SPOC-based blended learning mode can be adopted for further application of computer science teaching for deaf students.

\section{A. Helpful to Promote Educational Equality on the Basis of Accessible Construction of Resources}

Open educational resource originates from two values: "opportunity and openness", whose purposes lie in that "accessible on-line resource will make it available for everyone to learn and education more popular" ${ }^{\text {[9] }}$. The original intention of MOOC was "equality" and "sharing" ,which is to shrink educational gap. With the social development and further reform, education modernization has been progressively enhanced, but compared with general education, the education for the deaf is relatively weak. Higher education for the deaf without the involvement of on-line education, the superior 
course resource, will enlarge the gap, which goes against the original intention of cloud classroom in open educational resources. At present, there are many domestically well-known MOOC platforms. However, it is definitely hard to find a complete course for deaf students with existing complexity, learners, video accessibility and so on. In the long run, accessibility of on-line resources needs to strengthen to satisfy deaf students' lifelong learning.

\section{B. Helpful to Satisfy Individual Needs on the Basis of Improved Self-learning}

Physiological deficiencies like hearing loss in various degrees, different time, recovery training received or not, recovery results, different educational surroundings (in general school or special school) will make a big difference for the deaf students in the same education environment. Meanwhile, mainly relying on self-learning by means of visual sense, the deaf will perform a lowly effective result because of short attention span and stricture attention field caused by visual fatigue. United teaching mode in normal school will cause the teacher to consciously repeat key knowledge points, by which unsatisfactory learning effect appears because their learning initiatives are influenced at a certain degree. Fortunately, by SPOC-based blended learning, the deaf students can control their learning process by frequently watching teaching video at any time, any place despite of classroom teaching or classroom surroundings. What's more, the reusability of the resources will relieve their nervousness during learning and make them more devoted in learning. But it is found out that learning polarization appears more apparently, namely, those with capable learning are more suitable for this mode, while those with weak ability perform less effectively, which causes enlarged gap. Therefore, self-learning ability is the key for successful education and the key approach to shrink the gap.

\section{Flexible Organization of Teaching Resource and Activity on Basis of Intuition and Interactivity}

Traditional teaching for deaf students is based on paper text courses and the text is the main teaching carrier for explanation, with sign language teaching employed mainly and PPT, blackboard-writing, and oral language supplemented. Due to the reasons that deaf students lack of regular reading method and weak understanding of the text, which are caused by the big gap in reading between hearing students and the deaf ${ }^{[10]}$, the teachers for deaf education often find that the deaf students can hardly understand. Worse, sign languages with local accents in various areas make expression with great difference, together with weak signed words and inadequate professional expressions, which hinders students' improvement from learning. The teachers for deaf education are generally superior to sign language understanding because sign language is not their first mastered language, in which some hard of hearing students feel certainly difficult to communicate with them, which influences communication initiative. However, SPOC-based blended learning mode can supply diversified learning resources to satisfy the learners by transformation from paper reading to e-reading. Moreover, besides sign language communication, on-line typing communication in SPOC-based blended learning mode becomes the main communication way between teachers and students and among students. Compared with sign language and oral language communication, typing communication on-line can be recorded, through which the teacher can correct errors in emerging expressions at any time, which is more flexible to organize any learning activity. What needs to avoid is to repeat what the book says. To take full play of the advantage that the deaf are good at visual and spacious memorizing, tuition has to be highlighted in on-line learning resources for them to form perceptive presentation.

\section{CONCLUSION}

SPOC-based blended learning mode makes space and time for learning more flexible and improves the effectiveness and the pertinence of classroom interaction, which is suitable for deaf students' learning characteristics. By teaching experiment in one semester to test that it is really helpful to promote teaching effect of computer science and raise students' satisfaction. However, it is still necessary to carry out many rounds of teaching experiment to form a normal state of blended learning, so as to further amend and verify the learning mode.

\section{ACKNOWLEDGEMENT}

This research was financially supported by Youth Fund Project approved by MOE in 2017 "Research on Blended Learning Result of SPOC-based for Deaf Students from Self-learning Perspective” (17YJC880075), Education Planning Project approved by Beijing Union University in 2016 "Research on Blended Learning Mode of SPOC-based for Deaf Students”(Sk110201610).

\section{REFERENCES}

[1] Driscoll, M. Blended learning: Let's get beyond the hype[OL]. $<$ http://www-07 .ibm.com/services/pdf/blended_learning.pdf.>

[2] EDUCAUSE, The New Media Consortium. Blended Learnning[OL].The Horizon Report 2015 edition.

[3] Chen Ran, Yang Cheng, Design Research on SPOC-based Blended learning Mode, China Distance Education, 2015,(5):42-80.

[4] Kang Yeqin, New Era of On-line Education---SPOC, Education Research of THU, 2014,(1):85-93.

[5] He Bin, Cao Yang, SPOC, MOOC-based Teaching Process Creation, China Educational Technology, 2015,(3):22-29.

[6] Huang Ronghuai, Ma Ding, Zheng Lanqin, Zhang Haisen, Blended-learning-based Course Design Theory, China Educational Technology, 2009,(1):9-14.

[7] Yang Li, Zhang Liguo, Application Mode of SPOC in Traditional Higher Education, Modern Education Technology, 2016,(5):56-62.

[8] Fox, A.. From MOOCs to SPOCs[DB/OL]. (2013-12-16)[2015-02-20]. http://cacm.acm.org/ magazines/2013/12/169931-frommoocs-to-spocs/fulltext.

[9] Lv Jingjing, New Connotation Exploration on Blended Learning in Open University, Course Educational Research, 2015,(3):72-80

[10] Ran Ruoxi, Li Hanjing, Lv Huihua, Research and Realization on SETT-based Accessible Video Subtitle for Teaching, Journal of Beijing Union University, 2016, (7):88-92 